\title{
An analysis from the Quality Outcomes Database, Part 1. Disability, quality of life, and pain outcomes following lumbar spine surgery: predicting likely individual patient outcomes for shared decision-making
}

\author{
Matthew J. McGirt, MD, ${ }^{1}$ Mohamad Bydon, MD, ${ }^{2}$ Kristin R. Archer, PhD, DPT, ${ }^{3,4}$ \\ Clinton J. Devin, MD, ${ }^{5}$ Silky Chotai, MD, ${ }^{5}$ Scott L. Parker, MD, ${ }^{5}$ Hui Nian, PhD, ${ }^{6}$ \\ Frank E. Harrell Jr., PhD, ${ }^{6}$ Theodore Speroff, PhD, ${ }^{7,8}$ Robert S. Dittus, MD, MPH, ${ }^{7,8}$ \\ Sharon E. Philips, MS,${ }^{6}$ Christopher I. Shaffrey, MD, ${ }^{9}$ Kevin T. Foley, MD, ${ }^{10}$ and \\ Anthony L. Asher, MD, ${ }^{1}$ for QOD Vanguard Sites
}

\begin{abstract}
'Department of Neurological Surgery, Carolina Neurosurgery and Spine Associates, and Neurological Institute, Carolinas Healthcare System, Charlotte, North Carolina; ${ }^{2}$ Department of Neurological Surgery, Mayo Clinic, Rochester, Minnesota; ${ }^{3}$ Department of Orthopedic Surgery, Vanderbilt Spine Center, ${ }^{4}$ Department of Physical Medicine and Rehabilitation, and ${ }^{5}$ Department of Orthopedic Surgery and Neurological Surgery, Vanderbilt Spine Center, Vanderbilt University Medical Center, Nashville, Tennessee; ${ }^{\circ}$ Department of Biostatistics, Vanderbilt University School of Medicine, Nashville, Tennessee; ${ }^{7}$ Geriatric Research Education Clinical Center, Tennessee Valley Health System, Veterans Health Administration, Nashville, Tennessee; ${ }^{8}$ Departments of Medicine and Biostatistics, Division of General Internal Medicine and Public Health, Center for Health Services Research, Vanderbilt University School of Medicine, Nashville, Tennessee; 'Department of Neurosurgery, University of Virginia Medical Center, Charlottesville, Virginia; and ${ }^{10}$ Department of Neurosurgery, University of Tennessee Health Sciences Center, Semmes-Murphey Neurologic \& Spine Institute, Memphis, Tennessee
\end{abstract}

OBJECTIVE Quality and outcomes registry platforms lie at the center of many emerging evidence-driven reform models. Specifically, clinical registry data are progressively informing health care decision-making. In this analysis, the authors used data from a national prospective outcomes registry (the Quality Outcomes Database) to develop a predictive model for 12-month postoperative pain, disability, and quality of life (QOL) in patients undergoing elective lumbar spine surgery.

METHODS Included in this analysis were 7618 patients who had completed 12 months of follow-up. The authors prospectively assessed baseline and 12-month patient-reported outcomes (PROs) via telephone interviews. The PROs assessed were those ascertained using the Oswestry Disability Index (ODI), EQ-5D, and numeric rating scale (NRS) for back pain (BP) and leg pain (LP). Variables analyzed for the predictive model included age, gender, body mass index, race, education level, history of prior surgery, smoking status, comorbid conditions, American Society of Anesthesiologists (ASA) score, symptom duration, indication for surgery, number of levels surgically treated, history of fusion surgery, surgical approach, receipt of workers' compensation, liability insurance, insurance status, and ambulatory ability. To create a predictive model, each 12-month PRO was treated as an ordinal dependent variable and a separate proportionalodds ordinal logistic regression model was fitted for each PRO.

RESULTS There was a significant improvement in all PROs $(p<0.0001)$ at 12 months following lumbar spine surgery. The most important predictors of overall disability, QOL, and pain outcomes following lumbar spine surgery were employment status, baseline NRS-BP scores, psychological distress, baseline ODI scores, level of education, workers'

ABBREVIATIONS ASA = American Society of Anesthesiologists; $\mathrm{BMI}=$ body mass index; $\mathrm{BP}=$ back pain; $\mathrm{CAD}=\mathrm{coronary}$ artery disease; $\mathrm{Cl}=\mathrm{confidence}$ interval; IQR = interquartile range; $\mathrm{LP}=$ leg pain; $\mathrm{MCID}=$ minimal clinically important difference; $\mathrm{NRS}$ = numeric rating Scale; ODI = Oswestry Disability Index; OR = odds ratio; $\mathrm{PRO}=$ patient-reported outcome; QOD = Quality Outcomes Database; QOL = quality of life.

SUBMITTED May 6, 2016. ACCEPTED November 18, 2016.

INCLUDE WHEN CITING Published online May 12, 2017; DOI: 10.3171/2016.11.SPINE16526. 
compensation status, symptom duration, race, baseline NRS-LP scores, ASA score, age, predominant symptom, smoking status, and insurance status. The prediction discrimination of the 4 separate novel predictive models was good, with a c-index of 0.69 for ODI, 0.69 for EQ-5D, 0.67 for NRS-BP, and 0.64 for NRS-LP (i.e., good concordance between predicted outcomes and observed outcomes).

CONCLUSIONS This study found that preoperative patient-specific factors derived from a prospective national outcomes registry significantly influence PRO measures of treatment effectiveness at 12 months after lumbar surgery. Novel predictive models constructed with these data hold the potential to improve surgical effectiveness and the overall value of spine surgery by optimizing patient selection and identifying important modifiable factors before a surgery even takes place. Furthermore, these models can advance patient-focused care when used as shared decision-making tools during preoperative patient counseling.

https://thejns.org/doi/abs/10.3171/2016.11.SPINE16526

KEY WORDS QOD; Quality Outcomes Database; patient-reported outcomes; predictive model; disability; pain; quality of life; lumbar

$\mathrm{D}$ EGENERATIVE lumbar spine pathology is a common indication for spine surgery, particularly with the aging US population. Over the past 2 decades, there has been a $300 \%$ increase in the number of low-back surgeries and a corresponding increase in the incidence and prevalence of lumbar fusion operations. ${ }^{24,54,59,64} \mathrm{~A}$ recent analysis from the Agency for Healthcare Research and Quality found that the greatest proportion of overall health care expenditure in US hospitals is spent on spinal fusion, costing $\$ 12.8$ billion in 2011. ${ }^{66}$ The safety and effectiveness of spine surgery vary significantly at the individual patient level. Recent evidence suggests that as many as $25 \%$ of diagnostic and therapeutic spine interventions are unnecessary or ineffective. ${ }^{25,62}$ For this reason, providers, payers, and hospital systems all aim to identify which patient-specific or surgery-specific factors play significant roles in postoperative outcomes.

In the current era of patient-centered care, engaging patients in shared decision-making in their treatment planning is imperative. Shared decision-making is defined as a process "involving the patient and provider, both parties participating in the treatment decision-making process, requiring information sharing, and both parties agreeing to the treatment decision made." ${ }^{17,23}$ True informed decisionmaking can be achieved if patients are provided with the factual probability of outcomes based on their individual risk factors. When applied in the preoperative setting, predictive models developed using patient-specific and surgery-specific factors have the potential to help patients achieve realistic expectations regarding postsurgical goals, identify modifiable patient- and system-related characteristics that can influence outcomes, and allow for the most efficient and efficacious application of health care resources.

Predictive models have been used as a decision-making tool across various disease processes in medicine. ${ }^{9,10}$, 21,50,51,67,68 For example, Lee et al. introduced predictive models for complications ${ }^{42}$ and surgical site infection ${ }^{43}$ following spine surgery. These models were designed to estimate the likelihood of complications or surgical site infection occurring after spine surgery based on the patient's comorbidity profile and the invasiveness of the given surgery. ${ }^{42,43}$ Although this effort represents an important ad- vance in modeling spine outcomes and promoting shared decision-making, a validated prediction model capable of providing individualized predictions of patient-reported outcomes (PROs) following elective lumbar spine surgery has not been developed. The absence of predictive models focusing on PROs is of significant clinical and societal importance, precisely because PROs are rapidly becoming the key element in assessing the effectiveness of patient-centered care. This is largely due to documented discrepancies between patient and clinician assessments of symptoms and functional impairment. ${ }^{30}$ PROs, therefore, may be more reflective of underlying health status than physician-reported outcomes. PROs take on even greater relative importance in conditions where treatments are associated with lower rates of "observed" adverse outcomes (e.g., major morbidity or mortality), as has been reported for elective spine surgery. ${ }^{8}$ In this regard, the most conspicuous and potentially impactful care improvement opportunities in spine surgery involve optimizing outcomes of greatest importance to patients, specifically relief of pain and improvement of quality of life (QOL) as well as decrease of disability.

Using data from the Quality Outcomes Database (QOD), formerly known as the $\mathrm{N}^{2} \mathrm{QOD}$, we set out with the primary goal of creating a clinically relevant predictive model for postoperative disability, QOL, and pain severity.

\section{Methods The QOD Registry}

Data from patients undergoing elective spine surgery for degenerative lumbar disease were entered into the multicenter prospective QOD registry over a 2-year period. The QOD is designed to establish risk-adjusted expected morbidity rates for the most common lumbar surgical procedures performed by spine surgeons.$^{7,8}$ The QOD registry enrolls spine surgery patients from 74 participating centers across 26 US states via representative sampling and collects measures of surgical safety and PROs. ${ }^{49}$

\section{Inclusion and Exclusion Criteria}

Patients undergoing lumbar surgery performed for 
primary stenosis, spondylolisthesis, disc herniation, and symptomatic mechanical disc collapse, as well as patients undergoing revision surgery for recurrent same-level disc herniation and adjacent-segment disease, were eligible for inclusion. Exclusion criteria included the following: spinal infection, tumor, fracture, traumatic dislocation, deformity, pseudarthrosis, recurrent multilevel stenosis, neurological paralysis due to preexisting spinal disease or injury, age less than 18 years, and incarceration.

\section{Demographic Variables}

We recorded the following patient demographic variables when reviewing electronic medical records: age, gender, body mass index (BMI), American Society of Anesthesiologists (ASA) grade, history of surgery, history of diabetes, coronary artery disease (CAD), osteoporosis, dominant presenting symptom, presence of motor deficit on examination, symptom duration, diagnosis, preoperative ambulatory status, and surgery-specific variables, including approach (anterior, posterior), number of levels involved, need for arthrodesis, and presence/absence of an interbody graft. The following variables were obtained from the patient interview and then confirmed by reviewing the electronic medical records: race, smoking status, education, employment status, preoperatively employed but not working at the time of surgery, type of occupation, workers' compensation, liability insurance, and type of health insurance (private, uninsured, Medicaid, Medicare).

\section{Interviews and PRO Questionnaires}

Baseline (preoperative), 3-month, and 12-month postoperative disability, QOL, and pain levels were assessed either through telephone interviews conducted by a data coordinator not involved with clinical care, or through self-administration either during a clinic visit or by mail. The outcome scores were then entered into a national aggregate database through a secure, password-protected web-based portal (Research Electronic Data Capture). ${ }^{34}$ In these interviews, validated questionnaires were used to collect data on the following outcome measures: 1) disease-specific physical disability (established using the Oswestry Disability Index [ODI]);27 2) preferencebased QOL status (established using the EQ-5D instrument); ${ }^{26}$ and 3) pain (established using the numeric rating scale $[\mathrm{NRS}]$ for back pain $[\mathrm{BP}]$ and leg pain [LP]). ${ }^{41}$ The anxiety/depression domain of the EQ-5D was used to define psychological distress. As a part of the EQ-5D questionnaire, the patients are asked if they are anxious or depressed; the responses are captured as 1) not anxious or depressed, 2) moderately anxious or depressed, or 3 ) extremely anxious or depressed. Patients from sites for whom 12-month PROs were completed as of July 2015 were included in analyses.

\section{Statistical Analysis}

Medians and interquartile ranges (IQRs) for continuous variables and frequencies for categorical variables were calculated for demographic and clinical characteristics. Multivariable proportional-odds ordinal regression models were developed for each PRO measure: disability (ODI), pain (NRS-BP and NRS-LP), and QOL (EQ-5D). Patient-specific variables were included in the models: age, gender, BMI, race, education level, history of surgery, smoking status, comorbid conditions, ASA grade, symptom duration, predominant presenting symptom, workers' compensation, liability insurance, insurance status, ambulatory ability, and baseline PROs, as well as surgeryspecific variables such as number of levels, need for arthrodesis, and surgical approach.

We assumed a linear relationship for the number of surgical levels operated upon (range 1-4 levels), baseline ODI score, baseline EQ-5D score, and baseline NRS-BP, and a smooth relationship for age, BMI, and baseline NRSLP score using restricted cubic regression splines with 4 , 4 , and 3 knots, respectively. The locations of knots were chosen based on marginal quantiles for that variable. All other predictors were included as binary or categorical variables. Wald testing measured the importance of individual predictors by using the following formula: Wald chi-square value minus degree of freedom (to level the playing field) for each predictor. The higher the difference, the higher is the importance of that predictor in the model.

The effect of predictors on the probability of patients having better 12-month PRO scores was reported as an odds ratio (OR); the corresponding 95\% confidence interval (CI) was calculated using the Wald method. Calibration and discrimination of the model were internally validated using bootstrap resampling to estimate likely performance of the model on a new sample of patients. The model performance was measured by the c-index. A c-index value of 0.5 is considered a random predication and a value of 1 suggests that a model is perfectly discriminating. ${ }^{32,33}$ The c-index is generally smaller for ordinal endpoints than for binary outcomes, due to the difficulty of modelling outcomes such as ODI, EQ-5D, NRS-BP, and NRS-LP.

Risk-adjusted outcomes and probability of improvement in PROs for 2 hypothetical patients were calculated to provide an example of the models. In addition, the probability of achieving clinically meaningful outcome (minimal clinically important difference [MCID]) for ODI was derived for the hypothetical patients. The previously published value of MCID for ODI (14.9 points) was used. ${ }^{57}$ In an effort to evaluate whether the sites with low follow-up rates would affect the results of our model, we performed a sensitivity analysis by building supplemental predictive models for PROs only including patients from sites with 12-month follow-up rates greater than $80 \%$. The analysis was performed using the $\mathrm{R}$ (version 3.1.2; https://www. r-project.org) and regression modeling (rms; https://cran. r-project.org/package $=$ rms) statistical packages.

\section{Results}

A total of 10,705 patients undergoing elective spine surgery for degenerative lumbar disease were enrolled and eligible for 12-month follow-up at the time of analysis. Of those patients, 7618 (71.2\%) from 39 sites completed a 12-month interview, and data on these patients form the basis of the present analyses. 
TABLE 1. Patient demographic and clinical characteristics included in the model

\begin{tabular}{|c|c|}
\hline Variable & No. of Patients \\
\hline Age (Q1, Q2, Q3) & $7603(49,60,69)$ \\
\hline Gender (\%) & 7615 \\
\hline Male & $3941(52)$ \\
\hline Female & $3674(48)$ \\
\hline BMI (Q1, Q2, Q3) & $7599(25.8,29.3,33.9)$ \\
\hline Hispanic (\%) & 7598 \\
\hline Yes & $169(2)$ \\
\hline No & $7429(98)$ \\
\hline Race (\%) & 7618 \\
\hline Caucasian & $6900(90)$ \\
\hline African American & $504(7)$ \\
\hline Other & $214(3)$ \\
\hline Education (\%) & 7561 \\
\hline Less than high school & $423(6)$ \\
\hline High school diploma & $3174(42)$ \\
\hline 2-year college degree & $1415(19)$ \\
\hline 4-year college degree & $1500(20)$ \\
\hline Post-college & $1049(14)$ \\
\hline Smoker (\%) & 7547 \\
\hline No & $6182(82)$ \\
\hline Yes & $1365(18)$ \\
\hline Diabetes (\%) & 7617 \\
\hline Yes & $1283(17)$ \\
\hline No & $6334(83)$ \\
\hline CAD (\%) & 7604 \\
\hline Yes & $872(12)$ \\
\hline No & $6732(88)$ \\
\hline Osteoporosis (\%) & 7613 \\
\hline Yes & $370(5)$ \\
\hline No & $7243(95)$ \\
\hline Psychological distress (\%) & 7590 \\
\hline None & $3775(50)$ \\
\hline Moderate & $3255(43)$ \\
\hline Severe & $560(7)$ \\
\hline Dominant symptom (\%) & 7618 \\
\hline Back dominant & $1538(20)$ \\
\hline Leg dominant & $2662(35)$ \\
\hline Back $=$ leg ${ }^{*}$ & $3418(45)$ \\
\hline Motor deficit (\%) & 7607 \\
\hline Yes & $2115(28)$ \\
\hline No & $5492(72)$ \\
\hline Symptom duration (\%) & 7555 \\
\hline$<3 \mathrm{mos}$ & $916(12)$ \\
\hline$>3 \mathrm{mos}$ & $6639(88)$ \\
\hline Compensation (\%) & 7513 \\
\hline Yes & $291(4)$ \\
\hline No & $7222(96)$ \\
\hline
\end{tabular}

CONTINUED IN NEXT COLUMN »
» CONTINUED FROM PREVIOUS COLUMN

TABLE 1. Patient demographic and clinical characteristics included in the model

\begin{tabular}{|c|c|}
\hline Variable & No. of Patients \\
\hline Liability (\%) & 7461 \\
\hline Yes & $349(5)$ \\
\hline No & $7112(95)$ \\
\hline Insurance (\%) & 7601 \\
\hline Uninsured & $84(1)$ \\
\hline Medicare & $2777(37)$ \\
\hline Medicaid & $316(4)$ \\
\hline Veterans Affairs/government & $182(2)$ \\
\hline Private & $4242(55)$ \\
\hline Ambulation (\%) & 6994 \\
\hline Independent & $5990(85)$ \\
\hline With an assist device & $960(14)$ \\
\hline Nonambulatory & $44(1)$ \\
\hline Occupation (\%) & 7589 \\
\hline Sedentary & $1213(16)$ \\
\hline Light & $851(11)$ \\
\hline Medium & $841(11)$ \\
\hline Heavy & $659(9)$ \\
\hline Disability & $679(9)$ \\
\hline Retired & $2601(34)$ \\
\hline Others & $745(10)$ \\
\hline \multicolumn{2}{|l|}{ Baseline PROs (Q1, Q2, Q3) } \\
\hline ODI & $38,48,60$ \\
\hline$E Q-5 D$ & $0.36,0.60,0.77$ \\
\hline NRS-BP & $5.0,7.0,8.0$ \\
\hline NRS-LP & $5.0,8.0,9.0$ \\
\hline
\end{tabular}

Q1 = lower quartile; Q2 = median; Q3 = upper quartile.

* Indicates pain is both leg and back dominant.

\section{Patient Demographics and Surgical Characteristics}

Patient and surgical variables included in the model are summarized in Tables 1 and 2. The median age of the 7618 patients was 60 years (IQR 49-69 years). In regards to diagnoses, $36 \%$ of patients $(\mathrm{n}=2737)$ had disc herniation, $33 \%$ $(\mathrm{n}=2493)$ stenosis, $20 \%(\mathrm{n}=1505)$ spondylolisthesis, $6 \%$ $(\mathrm{n}=430)$ recurrent disc herniation, $5 \%(\mathrm{n}=378)$ adjacentsegment disease, and $1 \%(\mathrm{n}=72)$ symptomatic mechanical disc collapse. Decompression with fusion was performed in $36 \%$ ( $\mathrm{n}=2653$ ) of patients, whereas decompression alone was performed in the remaining $64 \%(\mathrm{n}=4873)$.

\section{Patient-Reported Outcomes}

Because patients elect surgery when suffering from disability or pain, and due to the effect of surgery, significant improvement in all outcomes was documented between baseline (preoperative) and 12-month scores: median ODI (48 [IQR 38-60] vs 18 [IQR 6-38], p < 0.001), EQ-5D (0.60 [IQR 0.36-0.77] vs 0.82 [IQR 0.7-1.0], p < 0.001), NRS-BP (7.0 [IQR 5-8] vs 2 [IQR 0-5], p < 0.001), and NRS-LP (8 [IQR 5-9] vs 1 [IQR 0-5], p < 0.001). 
TABLE 2. Surgery-related variables included in the models

\begin{tabular}{cc}
\hline \multicolumn{1}{c}{ Variable } & No. of Patients $(\%)$ \\
\hline ASA score & 7543 \\
\hline 1 & $503(7)$ \\
\hline 2 & $4214(56)$ \\
\hline 3 & $2826(37)$ \\
\hline No. of treated levels & 7199 \\
\hline 1 & $2818(39)$ \\
\hline 2 & $3098(43)$ \\
\hline 3 & $1011(14)$ \\
\hline 4 & $272(4)$ \\
\hline Approach & 7403 \\
\hline Posterior & $7266(98)$ \\
\hline Anterior & $137(2)$ \\
\hline Arthrodesis & 7526 \\
\hline None & $4873(65)$ \\
\hline Fusion w/ no interbody graft & $412(5)$ \\
\hline Fusion w/ interbody graft & $2241(30)$ \\
\hline
\end{tabular}

\section{Predictive Models}

The importance of each predictor included in each model is depicted in Fig. 1. The "overall" importance is an average of the normalized percentage importance of each predictor for each of the 4 models. Figure 2 summarizes the adjusted effects of predictors for the ODI, EQ-5D, NRS-BP, and NRS-LP models.

\section{Predictive Model for 12-Month Disability (ODI)}

The performance measure (c-index) of the ODI predictive model was 0.69 . Higher education $(p<0.0001)$, higher preoperative NRS-LP scores ( $\mathrm{p}<0.0001)$, and better baseline QOL ( $\mathrm{p}<0.0001)$ were associated with higher odds of having lower (better) disability outcomes. Regarding the type of surgery, compared with those undergoing fusion, the patients undergoing decompression only and those undergoing interbody fusion had higher odds of having better outcomes (lower ODI scores; $\mathrm{p}=0.0019$ ).

Older age $(p<0.0001)$, female sex $(p=0.0001)$, obesity $(\mathrm{p}=0.002)$, African American race $(\mathrm{p}<0.0001)$, smoking $(\mathrm{p}<0.0001)$, preoperative psychological distress $(\mathrm{p}<0.0001)$, dominant BP at presentation $(\mathrm{p}<0.0001)$, baseline motor deficit $(\mathrm{p}=0.0089)$, duration of symptoms greater than 3 months ( $p<0.0001)$, assist device for ambulation ( $\mathrm{p}=0.0002)$, unemployment $(\mathrm{p}<0.0001)$, workers' compensation ( $\mathrm{p}<0.0001)$, non-private health insurance $(\mathrm{p}<0.0001)$, worse baseline disability scores $(\mathrm{p}<0.0001)$, higher NRS-BP scores ( $\mathrm{p}<0.0001$ ), and higher ASA scores $(p<0.0001)$ were associated with lower odds of having better disability outcomes (lower ODI scores). Regarding the surgical variables, patients undergoing an anterior approach had higher odds of having worse 12-month disability scores $(\mathrm{p}=0.0108)$.

\section{Predictive Model for 12-Month QOL (EQ-5D)}

The performance measure (c-index) of the EQ-5D predictive model was 0.69 . Older age $(\mathrm{p}<0.0001)$, higher edu- cation ( $\mathrm{p}<0.0001)$, better preoperative QOL $(\mathrm{p}=0.0001)$, and higher preoperative LP scores $(\mathrm{p}=0.0012)$ had greater odds of having higher (better) 12-month QOL outcomes.

Obesity $(\mathrm{p}=0.0023)$, African American race $(\mathrm{p}=$ $0.0001)$, smoking $(\mathrm{p}<0.0001)$, psychological distress ( $\mathrm{p}$ $<0.0001)$, dominant BP at presentation $(\mathrm{p}<0.0001)$, duration of symptoms greater than 3 months ( $<<0.0001$ ), assist device for ambulation $(\mathrm{p}=0.0218)$, unemployment due to disability or employment with medium labor job ( $\mathrm{p}$ $<0.0001$ ), workers' compensation ( $\mathrm{p}<0.0001$ ), Medicaid, uninsured, or Veterans Affairs/government payer status ( $\mathrm{p}$ $=0.0011)$, worse baseline disability scores $(\mathrm{p}<0.0001)$, higher baseline BP scores ( $<<0.0001)$, and higher ASA grades $(p<0.0001)$ were associated with lower odds of having higher (better) QOL outcomes.

\section{Predictive Model for 12-Month Back Pain (NRS-BP)}

The performance measure (c-index) of the NRS-BP predictive model was 0.67 . Older age $(\mathrm{p}<0.0001)$, higher education level ( $\mathrm{p}<0.0001)$, and higher baseline QOL ( $\mathrm{p}$ $=0.0263$ ) had greater odds of resulting in lower (better) BP outcomes.

Worse baseline disability scores $(\mathrm{p}=0.0001)$, higher baseline BP scores $(p<0.0001)$, obesity $(p=0.0045)$, African American race $(\mathrm{p}<0.0001)$, being a smoker $(\mathrm{p}=$ $0.0001)$, psychological distress $(\mathrm{p}<0.0001)$, dominant BP as presenting symptom $(\mathrm{p}<0.0001)$, duration of symptom greater than 3 months $(\mathrm{p}<0.0001)$, not employed due to disability or employed in heavy- or medium-labor job ( $\mathrm{p}$ $<0.0001)$, workers' compensation ( $p<0.0001)$, Medicaid payer status $(\mathrm{p}=0.0027)$, and higher ASA score $(\mathrm{p}=$ 0.0002 ) were associated with lower odds of having lower (better) BP outcomes.

\section{Predictive Model for 12-Month Leg Pain (NRS-LP)}

The performance measure (c-index) of the NRS-LP predictive model was 0.64 . Older age $(\mathrm{p}=0.0005)$, higher education level $(p<0.0001)$, and arthrodesis $(p=0.0014)$, had higher odds of having lower (better) 12-month LP outcomes.

African American race $(\mathrm{p}<0.0001)$, psychological distress $(\mathrm{p}<0.0001)$, baseline motor deficit $(\mathrm{p}=0.0194)$, duration of symptoms greater than 3 months $(\mathrm{p}<0.0001)$, unemployment $(\mathrm{p}<0.0001)$, workers' compensation $(\mathrm{p}<$ $0.0001)$, liability insurance $(\mathrm{p}=0.0010)$, Medicaid payer status $(\mathrm{p}=0.0092)$, higher baseline disability scores $(\mathrm{p}<$ $0.0001)$, higher baseline BP scores $(\mathrm{p}<0.0001)$, and greater ASA scores $(p=0.0049)$ were associated with lower odds of having lower (better) LP outcomes.

\section{Hypothetical Patients A and B}

The predictive models can be used in the clinical setting to predict the PROs 12 months following spine surgery. Based on the model, we generated 2 hypothetical patients and predicted their 12-month PROs and probability of achieving MCID in PROs. Previously published MCID thresholds for ODI, EQ-5D, and NRS-LP and NRS-BP were used. ${ }^{57}$ As detailed in Table 3, our hypothetical Patient $\mathrm{A}$ is a 35-year-old white woman with a post-college level of education who had a sedentary job and private 


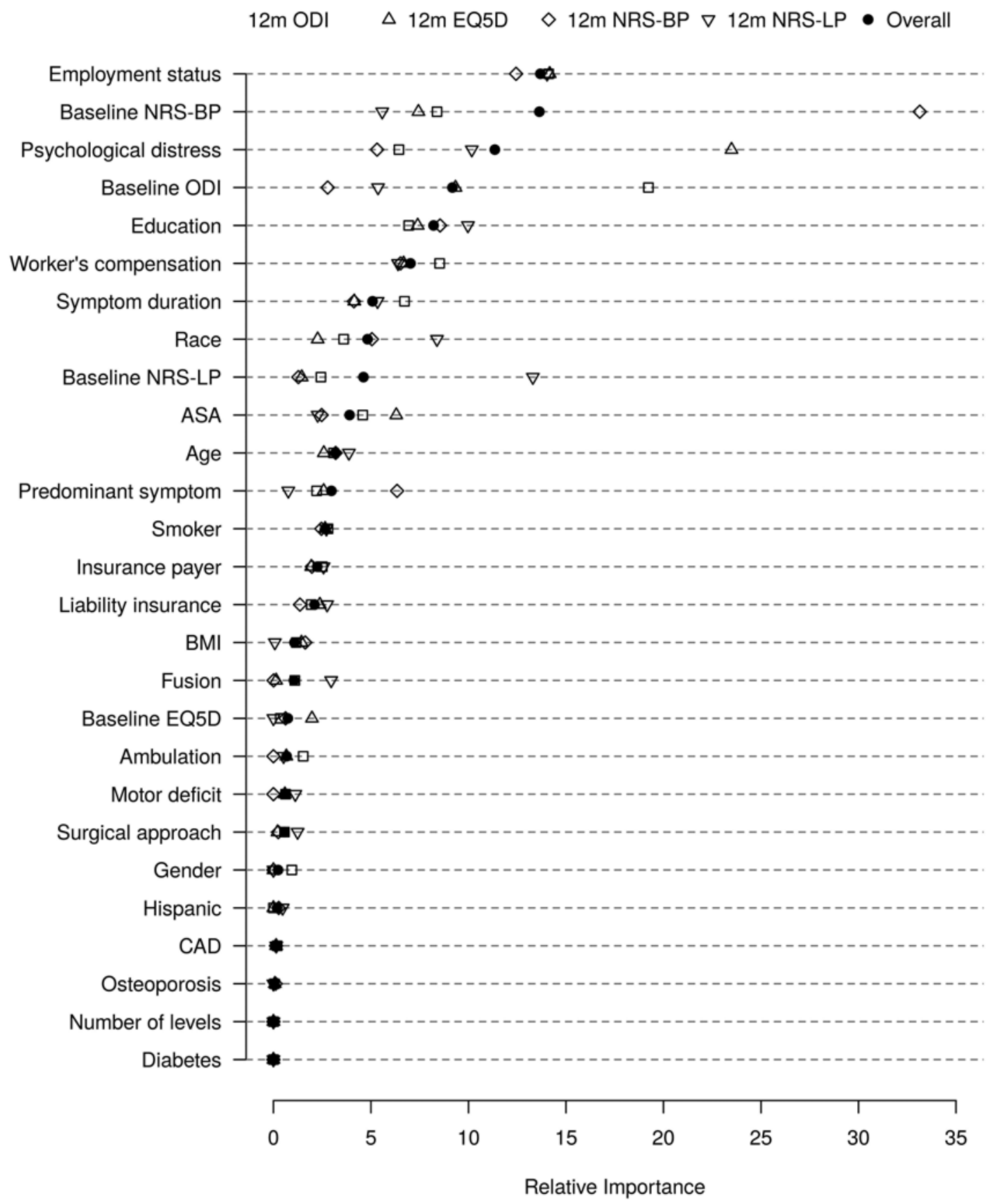

FIG. 1. Importance of predictors, measured by Wald chi-square value minus the degree of freedom of the predictor, based on multivariable models. The overall rank is based on the average of the normalized values of the 4 multivariable models.

health insurance. She had no other comorbidities, such as diabetes, anxiety, or depression, and presented with dominant LP that had been symptomatic for less than 3 months. Baseline PRO scores were as follows: ODI, 44; EQ-5D, 0.7 ; and NRS-BP and NRS-LP, 6 and 8, respectively. The patient underwent a 1-level laminectomy for disc herniation. The 12-month ODI score predicted by the model for this patient was 7.0 points (37-point improvement in ODI) and the probability of achieving a clinically meaningful improvement in ODI was $94.2 \%$. These results stand in contrast to those in Patient B (Table 3), who had a lower probability of achieving MCIDs for ODI (25.8\%) and the model-predicted mean ODI score improvement of 8.3 points (59.7 absolute 12-month ODI score). This comparison offers a dramatic example of the utility of this model with respect to informed decision-making. Specifically, Patient A could be reassured that she has a high probability of achieving success (at least success as measured by PROs) with the proposed intervention. Patient $\mathrm{B}$, however, would need to be counseled that his chance for success with the same operation is relatively low, and that he might want to defer the intervention until certain modifiable factors could be addressed (e.g., anxiety, obesity, smoking, proposed postsurgical work activities, etc.). Alternatively, 


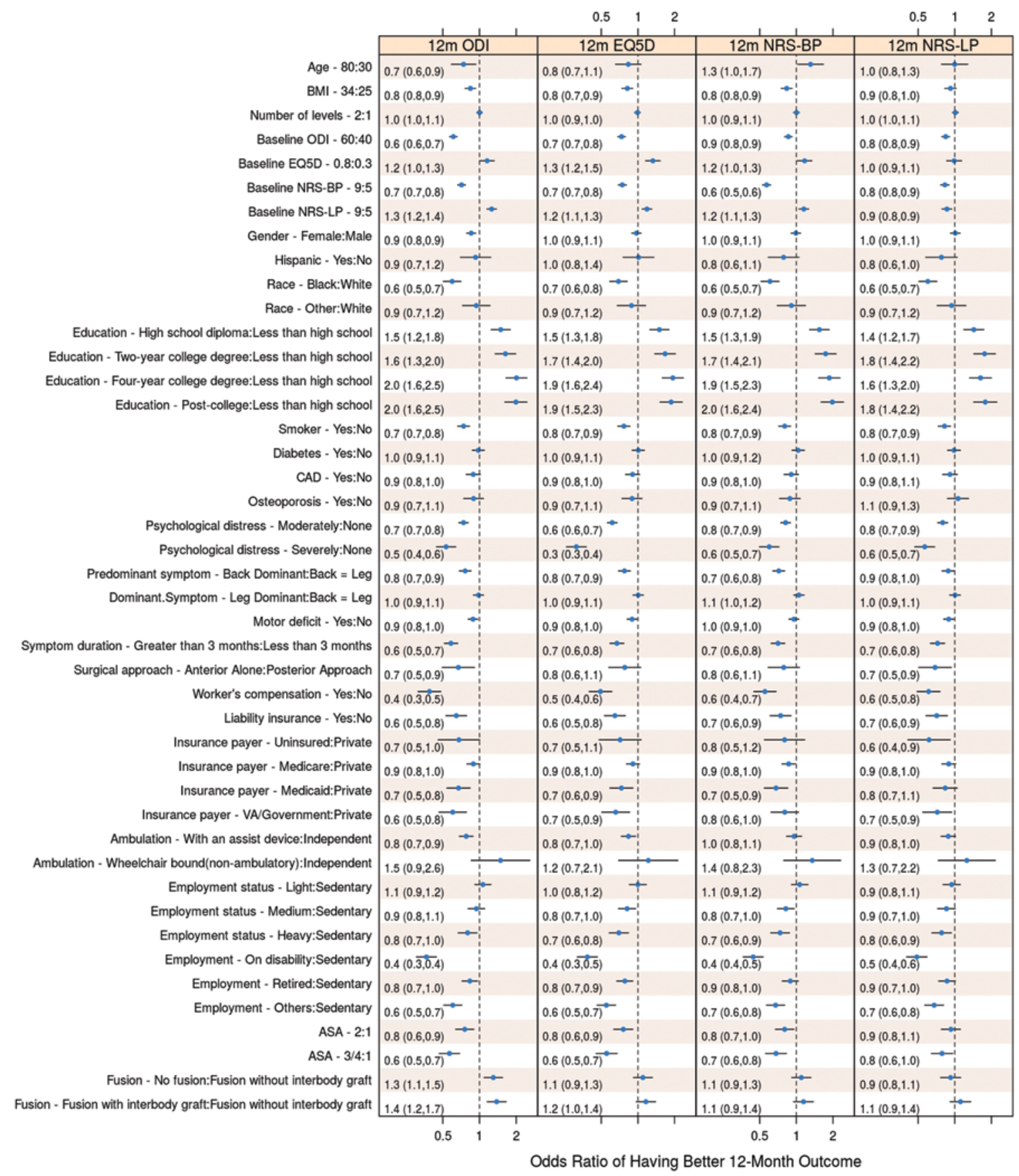

FIG. 2. Summary of ORs and $95 \% \mathrm{Cls}$ for ODI, EQ-5D, NRS-BP, and NRS-LP models. The values to the immediate right of some variables are quartiles. Figure is available in color online only.

he could be advised that alternate therapies might offer a greater or equivalent benefit while posing less risk. At the very least, such decision tools would help establish appropriate expectations with respect to the outcomes of various interventions, thus increasing the likelihood that the patient will be satisfied with his or her care. Additionally, this tool could be used by a variety of health care stakeholders to identify and prevent ineffective care before it occurs, thus improving the overall value of medical services. Of course, from a registry such as this with no nonsurgical patient cohort, one cannot estimate the likelihood of im- provement had surgery not been performed or estimate the effect of regression of the mean.

\section{Sensitivity Analysis}

Sensitivity analysis was performed for 2968 patients from 8 sites with 12-month follow-up rates greater than $80 \%$ (Supplemental Fig. 1). The model performance and the effect size of the predictors in the supplemental models were similar to the full model including all the patients with complete 12-month follow-up. 
TABLE 3. Predicted probabilities of improvement 12 months after lumbar surgery derived from predictive model for 2 hypothetical patients ( $A$ and $B$ )

\begin{tabular}{|c|c|c|}
\hline Characteristic & Patient A & Patient B \\
\hline Age & 35 & 66 \\
\hline $\mathrm{BMI}$ & 30 & 35 \\
\hline Gender & Female & Male \\
\hline Race & White & White \\
\hline Education & Post-college & Less than high school \\
\hline Prior Surgery & No & Yes \\
\hline Smoker & No & Yes \\
\hline Insurance & Private & Medicare \\
\hline Diabetes & No & Yes \\
\hline CAD & No & Yes \\
\hline Depression & No & Yes \\
\hline Anxiety & No & Yes \\
\hline Predominant symptom & LP & $\mathrm{BP}$ \\
\hline Motor deficit & No & No \\
\hline Duration of symptoms & $<3$ mos & $>3 \mathrm{mos}$ \\
\hline ASA grade & 1 & 2 \\
\hline Diagnosis & Disc herniation & Disc herniation \\
\hline No. of levels & 1 & 1 \\
\hline Surgical approach & Posterior & Posterior \\
\hline Fusion & No & No \\
\hline Occupation & Sedentary & Heavy manual labor \\
\hline Workers' compensation & No & Yes \\
\hline Liability insurance & No & Yes \\
\hline Baseline ODI & 44 & 68 \\
\hline Baseline EQ-5D & 0.7 & 0.3 \\
\hline Baseline NRS-BP & 6 & 9 \\
\hline Baseline NRS-LP & 8 & 8 \\
\hline \multicolumn{3}{|c|}{ Predicted probabilities (95\% Cl) } \\
\hline Mean ODI & 7.0 & 60.6 \\
\hline Achieving MCID for ODI* & $94.2 \%(92.6 \%-95.5 \%)$ & $25.8 \%(18.0 \%-35.5 \%)$ \\
\hline Improvement in ODI† & $97.8 \%(97.2 \%-98.3 \%)$ & $59.9 \%(48.4 \%-70.5 \%)$ \\
\hline Mean EQ-5D & 0.94 & 0.34 \\
\hline Improvement in EQ-5D† & $97.6 \%(96.9 \%-98.2 \%)$ & $53.0 \%(41.4 \%-64.4 \%)$ \\
\hline Mean NRS-BP & 1.3 & 7.8 \\
\hline Improvement in $\mathrm{BP} \dagger$ & $93.9 \%(92.2 \%-95.2 \%)$ & $56.8 \%(45.1 \%-67.8 \%)$ \\
\hline Mean NRS-LP & 1.2 & 6.7 \\
\hline Improvement in LP† & $96.7 \%(95.7 \%-97.5 \%)$ & $48.1 \%(36.5 \%-60.0 \%)$ \\
\hline
\end{tabular}

\section{Discussion}

\section{Model Performance}

Predictive models provide individualized risk-adjusted postoperative outcome estimations, which in the absence of nonsurgical outcome data have tremendous potential to assist providers during the preoperative assessment of patients and to improve patient engagement in shared decision-making concerning treatment planning. Using a prospective, multicenter, longitudinal registry, we developed
4 predictive models for 12-month PROs after elective surgery for degenerative lumbar spine pathology. In descending order of importance, the most important predictors of overall disability, QOL, and pain outcomes following lumbar spine surgery were patient employment status, baseline NRS-BP scores, psychological distress, baseline ODI scores, level of education, workers' compensation status, symptom duration, race, baseline NRS-LP scores, ASA score, age, predominant symptom, smoking status, and insurance status. 


\section{Predictors of Outcome}

Occupation-related factors, including employment status at the time of surgery and type of occupation, were the most important predictors of the overall outcomes. Patients not actively working (disability claim or retired) had significantly lower odds of having better outcomes at 12 months postoperatively than those who were actively employed. Furthermore, patients employed in mediumand heavy-labor jobs had lower odds of achieving better outcomes than those with a sedentary-type job. While these findings potentially can be explained in part by the presence of more severe back pathologies in patients with more laborious jobs and in those receiving disability funds, these factors cannot fully account for such findings. As such, the association between occupation and outcomes is likely multifactorial. Previous sociological models have revealed that patients' capacity for recovery and return to function also depends on psychological state, job satisfaction, physical demands at work, income, and social support. $5,20,31,47,52$

A patient's baseline functional status was also found to be an important predictor of overall outcomes. The impact of baseline functional status on postoperative outcomes following lumbar spine surgery is a consistent finding in the literature. . $^{11,12,19,28,36-38,44,46,48,65}$ Analogous to our results, numerous previous studies have demonstrated that the patients whose baseline disability, pain, and QOL scores are, on average, worse than those of others are more likely to have poorer outcomes at 12 months., ${ }^{3,14,48}$ Conversely, we found that patients with higher baseline NRS-LP scores had greater odds of having better outcomes. Pearson et al. reported that surgery in patients with higher preoperative LP scores yielded significantly better pain relief than in those with higher preoperative BP scores. ${ }^{58}$ This may be because the patients with higher LP scores often have associated radiculopathy or neurogenic claudication, which is typically more responsive to surgical decompression than BP. In a cross-sectional study assessing associations between patients' expectations for lumbar spine surgery and baseline characteristics, Mancuso and colleagues demonstrated that patients with greater preoperative disabilityfor whom the literature consistently demonstrates a lower odds of achieving better outcomes-have the greatest expectations for postoperative functional recovery. ${ }^{45}$ This finding highlights the importance of adjusting for varying degrees of baseline disability, pain, and QOL status when assessing 12-month outcomes. This also underscores the importance of shared preoperative decision-making, facilitated with evidence-based decision support tools, such as the predictive models presented here.

Patients' preoperative psychological distress was an important predictor of overall outcomes and it was the one of the most important predictors of postoperative 12-month QOL (EQ-5D). A number of previous studies have reported that preoperative psychological distress is associated with worse outcomes following lumbar spine surgery. 2,4,22,35,39,56,63 Sinikallio et al., in a prospective analysis of 96 patients, demonstrated that the patients with preoperative depression and those who had continuous depression postoperatively experienced poor outcomes. At the 2-year follow-up evaluation, the patients who recovered from de- pression demonstrated postoperative improvement similar to the patients who had normal mood preoperatively and postoperatively.$^{60} \mathrm{In}$ a recent randomized control trial, Archer et al. demonstrated that incorporating targeted cognitive behavioral therapy in postoperative care results in improved outcome 3 months after lumbar spine surgery. ${ }^{6}$ This suggests that medical and behavioral interventions for concomitant psychological disease during the preoperative and postoperative periods may help to improve outcomes in patients with psychological distress. We observed that a higher level of education was an important predictor for better overall PROs. Authors of previous studies have also indicated that higher education has a positive effect on patient outcomes. ${ }^{40,55,61}$ Further support of the importance of education on clinical outcomes is the observation of some authors that a correlation exists between lower levels of education and treatment noncompliance, and other healthcompromising behaviors. ${ }^{55}$

With respect to surgical procedures, the surgery-specific factors analyzed in the present study, including fusion, surgical approach, and number of vertebral levels involved, was observed to have a lower overall predictive importance compared with other variables (and, therefore, a lower impact on predicting PROs). These findings reinforce numerous and consistent previous observations that patient-specific factors are primary drivers of outcomes following spine surgery. 1,16,19,38,48,52

Based on our data, we found that other baseline patientspecific factors-workers' compensation, symptom duration, race, smoking status, preoperative comorbidities, and insurance status-also strongly influence outcomes following lumbar surgery, a finding consistent with those reported in a number of studies. $3,11,13,15,18,19,48$

\section{Application to Real-World Practice}

The 4 predictive models described provide individualized risk-adjusted postoperative outcome projections. The cases presented represent hypothetical case scenarios comparing patient characteristics that predict better or worse outcomes after surgical therapy for lumbar degenerative diseases. Although this information may potentially be used to tailor the application of invasive therapies (particularly to help avoid care that is highly likely to be ineffective) the authors caution that restriction of surgical therapy based solely on patient characteristics such as race, socioeconomic status, and/or age is inappropriate, potentially discriminatory, and is not the intended use of these models. In that regard, we would like to emphasize that no single variable is likely to influence ultimate outcomes, that all variables have differential effects in individual patients, and that all of the predictors used in this model have an additive effect on predicting surgical outcomes. The predictive models presented here are primarily intended to engage patients in shared decision-making and facilitate true patient-centered care. Furthermore, the decision to offer surgery to any given patient requires consideration of numerous factors including, but certainly not restricted to, likely longer-term (e.g., 12-month) outcomes. As long-term expected clinical outcomes are only one element of the surgical decision process, results of this model would not necessarily deter clinicians from operating on 
patients with negative predictors of outcome, such as low baseline function.

Probabilistic discussions regarding postoperative outcomes during preoperative assessment can assist providers in setting realistic presurgical expectations for patients and families and help improve patient satisfaction with care. Clinicians can use these tools to adjust modifiable patient characteristics preoperatively to help modify postoperative outcomes. They can also use predictive models to help identify patient populations to recognize potentially ineffective care before it is given, thus facilitating greater surgical effectiveness and increasing the overall value (cost-benefit ratio) of spine surgery. The tools can also be used to provide meaningful comparisons of performance between service providers, by allowing for the generation of risk-stratified benchmarks for care. By comparing actual and expected (i.e., risk-adjusted) outcomes, providers who typically take care of the sickest and highest-risk patients (e.g., those in tertiary care centers) can do so with diminished concern of financial penalty in an increasingly value-based reimbursement environment.

As predictive models can be challenging to apply in "real-world" clinic settings, we have created a user-friendly, online application that can be more easily used in the spine clinic to predict PROs (http://statcomp2.vanderbilt. edu:37212/app_0/). By enabling patient-specific probabilistic counseling at the point of care, we seek to facilitate involvement of all stakeholders in true, shared decisionmaking. This activity holds promise with respect to improving patient outcomes and increasing health care savings.

\section{Study Limitations and Strengths}

The limitations and weaknesses inherent in the current study have implications for the interpretation of its findings. Without controls, outcomes of patients can be compared but not outcomes of competing therapies. An intrinsic limitation of predictive models is the discrete number of variables that are inputted into its creation. In the present analysis, we included 30 patient-specific and surgeryspecific variables collected as a part of the multicenter QOD registry. It is possible that variables not collected and therefore not accounted for in this analysis will play a significant role in a patient's disability, QOL, and pain status after surgery. Such missing data would affect the performance of the models in discriminating accurately between observed and predicted outcomes. With exponentially increasing numbers of patients enrolled in the QOD registry, and with further refinement of variables collected, we will be able to update the predictive model and thereby increase its performance and accuracy.

Nonetheless, our risk-adjusted predictive models provide value as a starting point for patient-level assessment to guide shared decision-making and optimize outcomes at the individual patient and population levels. The c-index for our models was in the range of $0.64-0.69$, which reflects a "good" discrimination index. ${ }^{32,33}$ Finally, the patients included in the QOD registry are enrolled from 74 centers across the US representing all practice types, i.e., academic, community, small, large, rural, and urban., ${ }^{7,53}$ The diverse mix of practices included and patients en- rolled generate a representative sample of patients undergoing elective lumbar spine surgery, allowing these results to be generalizable (i.e., applicable) to most spinal surgery practices.

\section{Conclusions}

In this study we introduce 4 novel predictive models for PROs utilizing patient-specific and surgery-specific variables. PRO measures of treatment effectiveness at 12 months are significantly impacted by several preoperative patient-specific factors. Using these tools to optimize patient selection and improve modifiable factors may facilitate greater surgical effectiveness and increase the overall value (cost-benefit ratio) of spine surgery. Furthermore, these robust predictive models can be used as a shared decision-making tool during preoperative patient counseling. While additional studies and controlled therapeutic comparisons focused on better understanding the associations described in this analysis are clearly warranted, the current study demonstrates that patient-specific factors beyond medical comorbidities, surgical indications, and surgical approaches can play a significant role in influencing overall patient outcomes.

\section{Acknowledgments}

This work was supported in part through a grant from the Neurosurgery Research and Education Foundation (NREF).

\section{Appendix \\ Quality and Outcomes Database (QOD) Vanguard Sites}

Anthony L. Asher, MD, ${ }^{1}$ Matthew J. McGirt, MD, ${ }^{1}$ Clinton J. Devin, MD, ${ }^{2}$ Joseph S. Cheng, MD, ${ }^{2}$ Kevin T. Foley, MD, ${ }^{3}$ Jeffrey M. Sorenson, MD,${ }^{3}$ John J. Knightly, MD, ${ }^{4}$ Steven D. Glassman, MD, ${ }^{5}$ Thomas B. Briggs, MD, ${ }^{6}$ Adam Kremer, MD, ${ }^{7}$ Wesley E. Griffitt, MD ${ }^{8}$ Noam Y. Stadlan, MD, ${ }^{9}$ Thomas W. Grahm, MD,${ }^{10}$ Meic H. Schmidt, MD, ${ }^{11}$ Praveen Mummaneni, MD, ${ }^{12}$ and Mark E. Shaffrey, MD. ${ }^{13}$

${ }^{1}$ Department of Neurological Surgery, Carolina Neurosurgery and Spine Associates, and Neurological Institute, Carolinas Healthcare System, Charlotte, North Carolina; ${ }^{2}$ Department of Orthopedic Surgery and Neurosurgery, Vanderbilt Spine Center, Vanderbilt University Medical Center, Nashville, Tennessee; ${ }^{3}$ Department of Neurosurgery, University of Tennessee Health Sciences Center, Semmes-Murphey Neurological \& Spine Institute, Memphis, Tennessee; ${ }^{4}$ Department of Neurosurgery, Atlantic Neurosurgical Specialists, Morristown, New Jersey; ${ }^{5}$ Department of Orthopedic Surgery, University of Louisville, and the Norton Leatherman Spine Center, Louisville, Kentucky; ${ }^{6}$ Springfield Neurological and Spine Institute, Springfield, Missouri; 'Department of Neurosurgery, Brain and Spine Center, Holland, Michigan; ${ }^{8}$ Department of Neurosurgery, BayCare Clinic Neurological, Green Bay, Wisconsin; ' Department of Neurosurgery, North Shore University Health System, Skokie, Illinois; ${ }^{10}$ Department of Surgery, East Texas Medical Center, Tyler Neurosurgical, Tyler, Texas; ${ }^{11}$ Department of Neurosurgery, University of Utah, Salt Lake City, Utah; ${ }^{12}$ Department of Neurological Surgery, University of California, San Francisco, California; and ${ }^{13}$ Department of Neurosurgery, University of Virginia Medical Center, Charlottesville, Virginia.

\section{References}

1. Aalto TJ, Malmivaara A, Kovacs F, Herno A, Alen M, Salmi L, et al: Preoperative predictors for postoperative clinical 
outcome in lumbar spinal stenosis: systematic review. Spine (Phila Pa 1976) 31:E648-E663, 2006

2. Abtahi AM, Brodke DS, Lawrence BD, Zhang C, Spiker WR: Association between patient-reported measures of psychological distress and patient satisfaction scores after spine surgery. J Bone Joint Surg Am 97:824-828, 2015

3. Adogwa O, Parker SL, Shau DN, Mendenhall SK, Bydon A, Cheng JS, et al: Preoperative Zung depression scale predicts patient satisfaction independent of the extent of improvement after revision lumbar surgery. Spine J 13:501-506, 2013

4. Adogwa O, Verla T, Thompson P, Penumaka A, Kudyba K, Johnson K, et al: Affective disorders influence clinical outcomes after revision lumbar surgery in elderly patients with symptomatic adjacent-segment disease, recurrent stenosis, or pseudarthrosis: clinical article. J Neurosurg Spine 21:153159, 2014

5. Anderson PA, Schwaegler PE, Cizek D, Leverson G: Work status as a predictor of surgical outcome of discogenic low back pain. Spine (Phila Pa 1976) 31:2510-2515, 2006

6. Archer KR, Devin CJ, Vanston SW, Koyama T, Phillips SE, George SZ, et al: Cognitive-behavioral-based physical therapy for patients with chronic pain undergoing lumbar spine surgery: a randomized controlled trial. J Pain 17:7689, 2016

7. Asher AL, McCormick PC, Selden NR, Ghogawala Z, McGirt MJ: The National Neurosurgery Quality and Outcomes Database and NeuroPoint Alliance: rationale, development, and implementation. Neurosurg Focus 34(1):E2, 2013

8. Asher AL, Speroff T, Dittus RS, Parker SL, Davies JM, Selden N, et al: The National Neurosurgery Quality and Outcomes Database ( $\left.\mathrm{N}^{2} \mathrm{QOD}\right)$ : a collaborative North American outcomes registry to advance value-based spine care. Spine (Phila Pa 1976) 39 (22 Suppl 1):S106-S116, 2014

9. Aziz A, Shariat SF, Roghmann F, Brookman-May S, Stief CG, Rink M, et al: Prediction of cancer-specific survival after radical cystectomy in pT4a urothelial carcinoma of the bladder: development of a tool for clinical decision-making. BJU Int 117:272-279, 2016

10. Baan CA, Ruige JB, Stolk RP, Witteman JC, Dekker JM, Heine RJ, et al: Performance of a predictive model to identify undiagnosed diabetes in a health care setting. Diabetes Care 22:213-219, 1999

11. Bekelis K, Desai A, Bakhoum SF, Missios S: A predictive model of complications after spine surgery: the National Surgical Quality Improvement Program (NSQIP) 2005-2010. Spine J 14:1247-1255, 2014

12. Braybrooke J, Ahn H, Gallant A, Ford M, Bronstein Y, Finkelstein J, et al: The impact of surgical wait time on patientbased outcomes in posterior lumbar spinal surgery. Eur Spine J 16:1832-1839, 2007

13. Carey TS, Garrett JM: The relation of race to outcomes and the use of health care services for acute low back pain. Spine (Phila Pa 1976) 28:390-394, 2003

14. Carreon LY, Glassman SD, Howard J: Fusion and nonsurgical treatment for symptomatic lumbar degenerative disease: a systematic review of Oswestry Disability Index and MOS Short Form-36 outcomes. Spine J 8:747-755, 2008

15. Carreon LY, Glassman SD, Kantamneni NR, Mugavin MO, Djurasovic M: Clinical outcomes after posterolateral lumbar fusion in workers' compensation patients: a case-control study. Spine (Phila Pa 1976) 35:1812-1817, 2010

16. Chapin L, Ward K, Ryken T: Preoperative depression, smoking, and employment status are significant factors in patient satisfaction after lumbar spine surgery. J Spinal Disord Tech [epub ahead of print], 2015

17. Charles C, Gafni A, Whelan T: Shared decision-making in the medical encounter: what does it mean? (or it takes at least two to tango). Soc Sci Med 44:681-692, 1997

18. Chotai S, Parker SL, Sivaganesan A, Sielatycki JA, Asher
AL, McGirt MJ, et al: Effect of complications within 90 days on patient-reported outcomes 3 months and 12 months following elective surgery for lumbar degenerative disease. Neurosurg Focus 39(6): E8, 2015

19. Chotai S, Sivaganesan A, Parker SL, McGirt MJ, Devin CJ: Patient-specific factors associated with dissatisfaction after elective surgery for degenerative spine diseases. Neurosurgery $77: 157-163,2015$

20. Cole DC, Ibrahim S, Shannon HS, Scott FE, Eyles J: Work and life stressors and psychological distress in the Canadian working population: a structural equation modelling approach to analysis of the 1994 National Population Health Survey. Chronic Dis Can 23:91-99, 2002

21. Danciu SC, Klein L, Hosseini MM, Ibrahim L, Coyle BW, Kehoe RF: A predictive model for survival after in-hospital cardiopulmonary arrest. Resuscitation 62:35-42, 2004

22. Daubs MD, Norvell DC, McGuire R, Molinari R, Hermsmeyer JT, Fourney DR, et al: Fusion versus nonoperative care for chronic low back pain: do psychological factors affect outcomes? Spine (Phila Pa 1976) 36 (21 Suppl):S96-S109, 2011

23. Department of Health and Human Services: Protection of human subjects; reports of the President's Commission for the Study of Ethical Problems in Medicine and Biomedical and Behavioral Research-Office of the Assistant Secretary for Health, HHS. Notice of availability of reports. Fed Regist 48:34408-34412, 1983

24. Deyo RA, Mirza SK, Martin BI, Kreuter W, Goodman DC, Jarvik JG: Trends, major medical complications, and charges associated with surgery for lumbar spinal stenosis in older adults. JAMA 303:1259-1265, 2010

25. Epstein NE, Hood DC: "Unnecessary" spinal surgery: A prospective 1-year study of one surgeon's experience. Surg Neurol Int 2:83, 2011

26. EuroQol Group: EuroQol-a new facility for the measurement of health-related quality of life. Health Policy 16:199208, 1990

27. Fairbank JC, Pynsent PB: The Oswestry Disability Index. Spine (Phila Pa 1976) 25:2940-2952, 2000

28. Franklin GM, Haug J, Heyer NJ, McKeefrey SP, Picciano JF: Outcome of lumbar fusion in Washington State workers' compensation. Spine (Phila Pa 1976) 19:1897-1904, 1994

29. Ghogawala Z, Shaffrey CI, Asher AL, Heary RF, Logvinenko T, Malhotra NR, et al: The efficacy of lumbar discectomy and single-level fusion for spondylolisthesis: results from the NeuroPoint-SD registry: clinical article. J Neurosurg Spine 19:555-563, 2013

30. Gliklich RE, Dreyer NA (eds): Registries for Evaluating Patient Outcomes: A User's Guide. Rockville, MD: Agency for Healthcare Research and Quality, April 2007

31. Gum JL, Glassman SD, Carreon LY: Is type of compensation a predictor of outcome after lumbar fusion? Spine (Phila Pa 1976) 38:443-448, 2013

32. Harrell FE Jr, Califf RM, Pryor DB, Lee KL, Rosati RA: Evaluating the yield of medical tests. JAMA 247:2543-2546, 1982

33. Harrell FE Jr, Lee KL, Califf RM, Pryor DB, Rosati RA: Regression modelling strategies for improved prognostic prediction. Stat Med 3:143-152, 1984

34. Harris PA, Taylor R, Thielke R, Payne J, Gonzalez N, Conde JG: Research electronic data capture (REDCap) - a metadata-driven methodology and workflow process for providing translational research informatics support. J Biomed Inform 42:377-381, 2009

35. Hoff RA, Rosenheck RA, Meterko M, Wilson NJ: Mental illness as a predictor of satisfaction with inpatient care at Veterans Affairs hospitals. Psychiatr Serv 50:680-685, 1999

36. Iversen MD, Daltroy LH, Fossel AH, Katz JN: The prognostic importance of patient pre-operative expectations of 
surgery for lumbar spinal stenosis. Patient Educ Couns 34:169-178, 1998

37. Junge A, Dvorak J, Ahrens S: Predictors of bad and good outcomes of lumbar disc surgery. A prospective clinical study with recommendations for screening to avoid bad outcomes. Spine (Phila Pa 1976) 20:460-468, 1995

38. Katz JN, Stucki G, Lipson SJ, Fossel AH, Grobler LJ, Weinstein JN: Predictors of surgical outcome in degenerative lumbar spinal stenosis. Spine (Phila Pa 1976) 24:2229-2233, 1999

39. Kohlboeck G, Greimel KV, Piotrowski WP, Leibetseder M, Krombholz-Reindl M, Neuhofer R, et al: Prognosis of multifactorial outcome in lumbar discectomy: a prospective longitudinal study investigating patients with disc prolapse. Clin J Pain 20:455-461, 2004

40. Laaksonen M, Talala K, Martelin T, Rahkonen O, Roos E, Helakorpi S, et al: Health behaviours as explanations for educational level differences in cardiovascular and all-cause mortality: a follow-up of 60000 men and women over 23 years. Eur J Public Health 18:38-43, 2008

41. Langley GB, Sheppeard H: The visual analogue scale: its use in pain measurement. Rheumatol Int 5:145-148, 1985

42. Lee MJ, Cizik AM, Hamilton D, Chapman JR: Predicting medical complications after spine surgery: a validated model using a prospective surgical registry. Spine J 14:291-299, 2014

43. Lee MJ, Cizik AM, Hamilton D, Chapman JR: Predicting surgical site infection after spine surgery: a validated model using a prospective surgical registry. Spine J 14:2112-2117, 2014

44. Lee MJ, Shonnard N, Farrokhi F, Martz D, Chapman J, Baker R, et al: The Spine Surgical Care and Outcomes Assessment Program (Spine SCOAP): a surgeon-led approach to quality and safety. Spine (Phila Pa 1976) 40:332-341, 2015

45. Mancuso CA, Duculan R, Stal M, Girardi FP: Patients' expectations of lumbar spine surgery. Eur Spine J 24:23622369, 2015

46. Mannion AF, Elfering A, Staerkle R, Junge A, Grob D, Dvorak J, et al: Predictors of multidimensional outcome after spinal surgery. Eur Spine J 16:777-786, 2007

47. Maxwell TD, Gatchel RJ, Mayer TG: Cognitive predictors of depression in chronic low back pain: toward an inclusive model. J Behav Med 21:131-143, 1998

48. McGirt MJ, Sivaganesan A, Asher AL, Devin CJ: Prediction model for outcome after low-back surgery: individualized likelihood of complication, hospital readmission, return to work, and 12-month improvement in functional disability. Neurosurg Focus 39(6):E13, 2015

49. McGirt MJ, Speroff T, Dittus RS, Harrell FE Jr, Asher AL: The National Neurosurgery Quality and Outcomes Database $\left(\mathrm{N}^{2} \mathrm{QOD}\right)$ : general overview and pilot-year project description. Neurosurg Focus 34(1):E6, 2013

50. McLaughlin DF, Niles SE, Salinas J, Perkins JG, Cox ED, Wade CE, et al: A predictive model for massive transfusion in combat casualty patients. J Trauma 64 (2 Suppl):S57S63, 2008

51. Michaelson JS, Chen LL, Bush D, Fong A, Smith B, Younger $\mathrm{J}$ : Improved web-based calculators for predicting breast carcinoma outcomes. Breast Cancer Res Treat 128:827-835, 2011

52. Mroz TE, Norvell DC, Ecker E, Gruenberg M, Dailey A, Brodke DS: Fusion versus nonoperative management for chronic low back pain: do sociodemographic factors affect outcome? Spine (Phila Pa 1976) 36 (21 Suppl):S75-S86, 2011

53. Mummaneni PV, Whitmore RG, Curran JN, Ziewacz JE, Wadhwa R, Shaffrey CI, et al: Cost-effectiveness of lumbar discectomy and single-level fusion for spondylolisthesis: experience with the NeuroPoint-SD registry. Neurosurg Focus 36(6):E3, 2014
54. North RB, Kidd D, Shipley J, Taylor RS: Spinal cord stimulation versus reoperation for failed back surgery syndrome: a cost effectiveness and cost utility analysis based on a randomized, controlled trial. Neurosurgery 61:361-369, 2007

55. Olson PR, Lurie JD, Frymoyer J, Walsh T, Zhao W, Morgan TS, et al: Lumbar disc herniation in the Spine Patient Outcomes Research Trial: does educational attainment impact outcome? Spine (Phila Pa 1976) 36:2324-2332, 2011

56. Pakarinen M, Vanhanen S, Sinikallio S, Aalto T, Lehto SM, Airaksinen O, et al: Depressive burden is associated with a poorer surgical outcome among lumbar spinal stenosis patients: a 5-year follow-up study. Spine J 14:2392-2396, 2014

57. Parker SL, Adogwa O, Paul AR, Anderson WN, Aaronson $\mathrm{O}$, Cheng JS, et al: Utility of minimum clinically important difference in assessing pain, disability, and health state after transforaminal lumbar interbody fusion for degenerative lumbar spondylolisthesis. J Neurosurg Spine 14:598-604, 2011

58. Pearson A, Blood E, Lurie J, Abdu W, Sengupta D, Frymoyer JW, et al: Predominant leg pain is associated with better surgical outcomes in degenerative spondylolisthesis and spinal stenosis: results from the Spine Patient Outcomes Research Trial (SPORT). Spine (Phila Pa 1976) 36:219-229, 2011

59. Ragab A, Deshazo RD: Management of back pain in patients with previous back surgery. Am J Med 121:272-278, 2008

60. Sinikallio S, Aalto T, Airaksinen O, Lehto SM, Kröger H, Viinamäki H: Depression is associated with a poorer outcome of lumbar spinal stenosis surgery: a two-year prospective follow-up study. Spine (Phila Pa 1976) 36:677-682, 2011

61. Slover J, Abdu WA, Hanscom B, Weinstein JN: The impact of comorbidities on the change in Short-Form 36 and Oswestry scores following lumbar spine surgery. Spine (Phila Pa 1976) 31:1974-1980, 2006

62. Smith M, Saunders R, Stuckhardt L, McGinnis JM (eds): Best Care at Lower Cost: The Path to Continuously Learning Health Care in America. Washington, DC: National Academies Press, 2013

63. Trief PM, Ploutz-Snyder R, Fredrickson BE: Emotional health predicts pain and function after fusion: a prospective multicenter study. Spine (Phila Pa 1976) 31:823-830, 2006

64. Weiner DK, Kim YS, Bonino P, Wang T: Low back pain in older adults: are we utilizing healthcare resources wisely? Pain Med 7:143-150, 2006

65. Weinstein JN, Tosteson TD, Lurie JD, Tosteson AN, Hanscom B, Skinner JS, et al: Surgical vs nonoperative treatment for lumbar disk herniation: the Spine Patient Outcomes Research Trial (SPORT): a randomized trial. JAMA 296:24412450, 2006

66. Weiss AJ, Elixhauser A, Andrews RM: Characteristics of Operating Room Procedures in U.S. Hospitals, 2011. Rockville, MD: Agency for Healthcare Research and Quality, 2014 (https://www.hcup-us.ahrq.gov/reports/statbriefs/ sb170-Operating-Room-Procedures-United-States-2011.jsp) [Accessed December 6, 2016]

67. Wong HS, Subramaniam S, Alias Z, Taib NA, Ho GF, Ng $\mathrm{CH}$, et al: The predictive accuracy of PREDICT: a personalized decision-making tool for Southeast Asian women with breast cancer. Medicine (Baltimore) 94:e593, 2015

68. Xylinas E, Kluth L, Passoni N, Trinh QD, Rieken M, Lee RK, et al: Prediction of intravesical recurrence after radical nephroureterectomy: development of a clinical decisionmaking tool. Eur Urol 65:650-658, 2014

\section{Disclosures}

Dr. McGirt has served as a consultant to Stryker. Dr. Devin has served as a consultant to PACIRA and as a defense expert witness for Medtronic. Dr. Shaffrey has served as a consultant to 
Medtronic, NuVasive, K2M, and Zimmer-Biomet; has direct stock ownership in NuVasive; and is a patent holder for Medtronic, NuVasive, and Zimmer-Biomet. Dr. Foley has served as a consultant to Medtronic; has direct stock ownership in Medtronic, NuVasive, SpineWave, and Discgenics; is a patent holder for Medtronic and NuVasive; and has received royalties from Medtronic.

\section{Author Contributions}

Conception and design: Asher, McGirt. Acquisition of data: Chotai, Nian. Analysis and interpretation of data: Chotai, Nian, Harrell. Drafting the article: Asher, Chotai, Parker. Critically revising the article: Asher, McGirt, Archer, Chotai, Harrell, Speroff. Reviewed submitted version of manuscript: Asher, McGirt, Bydon, Archer, Chotai, Parker, Nian, Harrell, Speroff, Dittus, Shaffrey, Foley. Statistical analysis: McGirt, Nian, Harrell. Administrative/technical/material support: Chotai, Philips. Study supervision: Asher, McGirt, Bydon, Harrell.

\section{Supplemental Information \\ Online-Only Content}

Supplemental material is available with the online version of the article.

Supplemental Figures. https://thejns.org/doi/suppl/10.3171/ 2016.11.SPINE16526.

\section{Companion Papers}

Asher AL, Devin CJ, Archer KR, Chotai S, Parker SL, Bydon M, et al: An analysis from the Quality Outcomes Database, Part 2. Predictive model for return to work after elective surgery for lumbar degenerative disease. DOI: 10.3171/2016.8.SPINE16527.

\section{Correspondence}

Anthony L. Asher, Department of Neurosurgery, Carolina Neurosurgery and Spine Associates, 225 Baldwin Rd., Charlotte, NC 28204. email: tony.asher@cnsa.com. 